\title{
A Cultura do Algodão Sustentável no Brasil
}

\author{
The Sustainable Cotton Culture in Brazil
}

WITKOSKI, Silvana Silva Reiter; Mestranda; Universidade da Região de Joinville (Univille). vanawitkoski@gmail.com

MORGENSTERN, Elenir Carmen; Doutora em Design; Pontifícia Universidade Católica do Rio de Janeiro (PUC-RIO).

elenir.m@gmail.com

\section{Resumo}

$\mathrm{O}$ artigo, configurando-se em recorte de pesquisa do Mestrado Profissional em Design, reflete acerca dos processos de cultivo, colheita, beneficiamento e mercadologia da principal fibra utilizada na indústria têxtil, que é a fibra do algodão. Intenciona-se propiciar ao leitor conhecimentos dos materiais utilizados na produção de vestuário, destacando-se procedimentos sustentáveis na produção da matéria-prima. A metodologia para o desenvolvimento da investigação englobou estudos bibliográficos, analisando aspectos relacionados ao agronegócio do algodão sustentável nos dias atuais. $O$ artigo descreve o que é a fibra do algodão, relata a história do seu cultivo, apresenta problemáticas vinculadas ao consumo e aborda a cultura do algodão sustentável no Brasil. As principais contribuições referem-se à conscientização dos agentes produtores e consumidores no tocante aos problemas e às perspectivas no que tange às práticas produtivas e mercadológicas que cercam o cultivo do algodão no Brasil.

Palavras-Chave: fibras têxteis; consumo de moda; algodão sustentável.

\begin{abstract}
The article, as a part of the research that has been developed at the master's degree in Design, reflects on the cultivation, crop, improvement and marketing processes of the main fiber utilized in the textile industry, i.e., the cotton one. We want to give the reader information about the materials used in the clothing production, emphasizing sustainable procedures in order to obtain the raw material. The approach applied in our investigation embraces bibliographical studies, analyzing features related to the sustainable cotton agribusiness nowadays. The text describes what a cotton fiber is, tells its cultivation story, presents problems linked to the consumption and focuses on the sustainable cotton culture in Brazil. The most relevant contributions refer to the awareness of agents involved in the production and consumers about the issues and the perspectives that surround the productive and marketing practices at cotton culture in Brazil.
\end{abstract}

Keywords: textile fibers; fashion consumption; sustainable cotton. 


\section{Introdução}

Uma das maiores áreas da economia mundial está ligada à indústria têxtil/moda, que desenvolve produtos diversificados buscando atender a todos os segmentos, porém ela é uma das mais poluentes, perdendo apenas para a indústria automobilística. Os temas sustentabilidade e meio ambiente são abordados desde a década de 1960. Na atualidade, por conta dos graves problemas ambientais que englobam a cadeia têxtil, questões que envolvem esse setor estão sempre em pauta. Entre todos os produtos têxteis comercializados, a matéria-prima mais utilizada atualmente é o algodão. Seu cultivo dá-se em muitos países e a produção possui considerável demanda, mas os resultados e danos são também significativos.

Este artigo contextualiza a cultura do algodão sustentável, que vem ao encontro da busca por iniciativas menos agressivas ao meio ambiente, começando pela produção da matéria-prima. Em seu desdobramento, o artigo destaca o que são as fibras têxteis e apresenta um enfoque histórico acerca do algodão no Brasil e no mundo, relatando fatores que impulsionam os agentes consumidores nas aquisições de novas peças do vestuário. Com ênfase na sustentabilidade e no meio ambiente, são salientados o cultivo do algodão sustentável, os procedimentos usados na produção da matéria-prima, as certificações envolvidas no agronegócio e as técnicas necessárias para a obtenção das fibras.

\section{Fibras Têxteis}

A matéria-prima para a produção de tecidos que são transformados em roupas do vestuário, cama, mesa e banho e demais peças artesanais e manufaturadas são as fibras têxteis. Aguiar Neto (1996, p. 13) descreve que, de acordo com a American Society for Testing and Materials (Sociedade Americana para Teste de Materiais - ASTM), que desenvolve e publica normas técnicas para materiais, produtos, sistemas e serviços, "fibra têxtil é um material que se caracteriza por apresentar um comprimento pelo menos 100 vezes superior à sua largura ou diâmetro". Araújo e Castro (1986, p. 1) complementam que "as fibras têxteis são elementos filiformes caracterizados pela flexibilidade, finura e grande comprimento em relação à dimensão transversal máxima, sendo aptas para aplicações têxteis".

Com as fibras, são produzidos os fios que dão origem aos tecidos. Daniel (2011, p. 21) explica que "as fibras são transformadas em fios pelo processo de fiação e os fios, por sua vez, diferem entre si e dependem do comprimento das fibras, que podem ser longas ou contínuas, como os filamentos de poliéster, poliamida, etc., como as fibras de seda, ou curtas, como as fibras de algodão ou lã". Com base no produto que se deseja criar, é necessário utilizar o material correto, conhecer as características da fibra envolvida na fabricação, a fim de se ter o resultado esperado (AGUIAR NETO, 1996).

As fibras estão divididas em naturais e químicas. Daniel (2011, p. 25) afirma que "as fibras naturais são encontradas prontas na natureza e precisam apenas de alguns processos químicos e físicos para serem transformadas em fios". Elas podem ser: vegetais, animais e minerais. Já as fibras químicas são produzidas por meio de processos químicos realizados pelo próprio homem e são de dois tipos: artificiais e sintéticas. As fibras artificiais são quimicamente confeccionadas, mas a sua matéria-prima é natural, normalmente celulose, como viscose e acetato. Já as sintéticas são feitas de matérias-primas provenientes das indústrias química e petroquímica, como poliéster, poliamida e elastano. 0 esquema da figura 1, a seguir, apresenta a classificação geral das fibras, separando-as em: naturais, ou seja, vegetais, animais e minerais; e químicas, distribuídas em 
artificiais e sintéticas.

Figura 1 - Classificação geral das fibras.

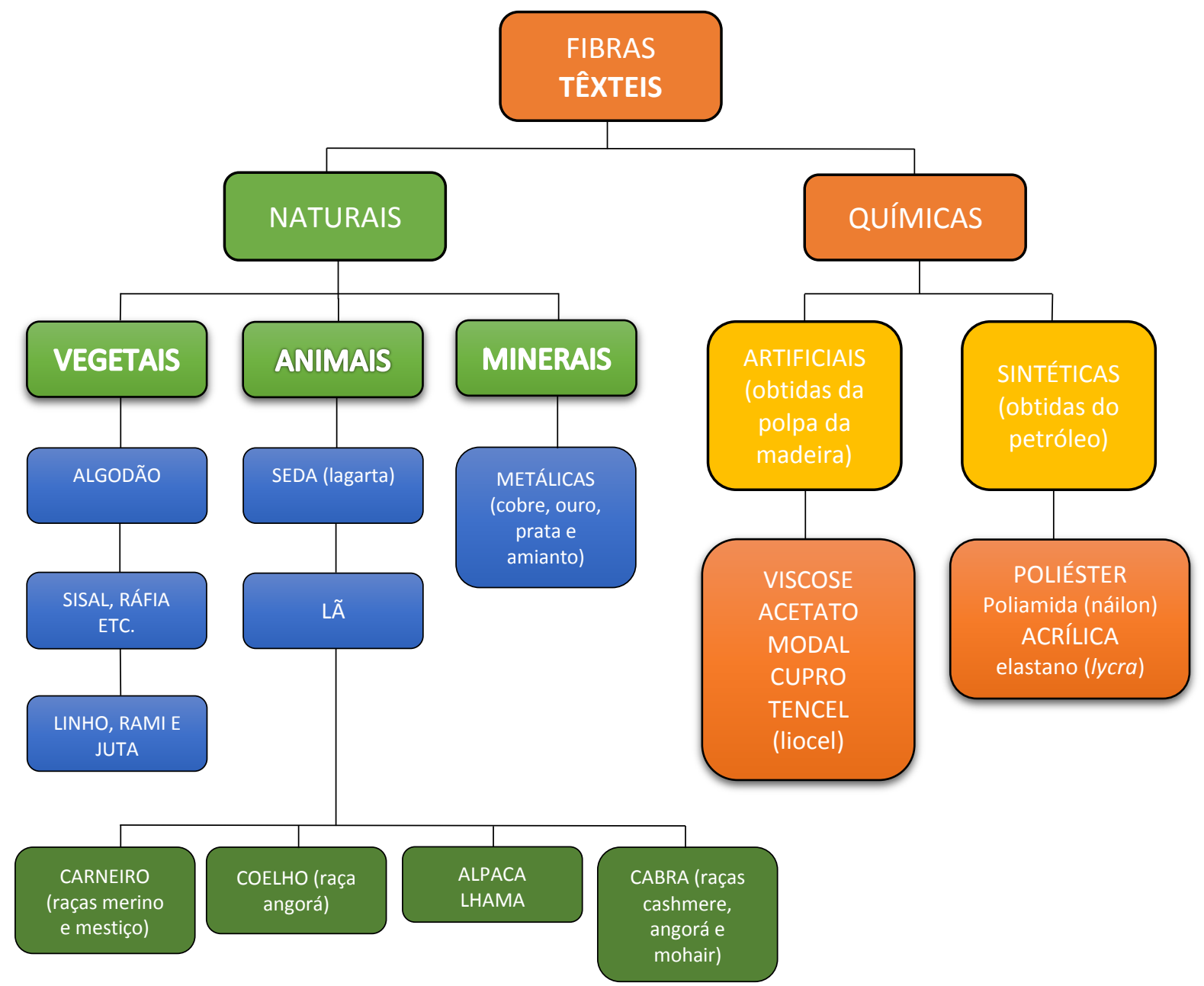

Fonte: adaptado de Daniel (2011, p. 24)

Todo material que possui a capacidade de produzir fios, seja proveniente da natureza, seja quimicamente produzido, é considerado uma fibra têxtil. A indústria utiliza fibras de diferentes espécies, naturais e químicas, mas, de todas elas, o algodão é o mais empregado para a fabricação de tecidos em geral. Daniel (2011) diz que o algodão é uma fibra vegetal. Das fibras têxteis, é uma das mais antigas do mundo e a mais usada hoje. Sua fibra forma-se em torno da semente do algodoeiro e, segundo o referido autor, reflete aproximadamente $50 \%$ da produção mundial anual de fibras.

Analisando o seu uso no vestuário, podemos verificar que a fibra do algodão também é a mais utilizada, pura ou em mistura com outras fibras: "Cerca de três quartos da população mundial a utiliza no vestuário" (CHATAIGNIER, 2006, p. 39). Filiada ao gênero Gossypium Hirsutum Linn, pertencente à família Malvaceae e conhecida popularmente como algodão, "a fibra do algodão é um pelo que se desenvolve de uma única célula epidérmica do tegumento externo da semente" (SALEM, 2010, p. 15). A figura 2 exibe uma plantação, com foco no algodão. 
Figura 2 - Plantação de algodão.

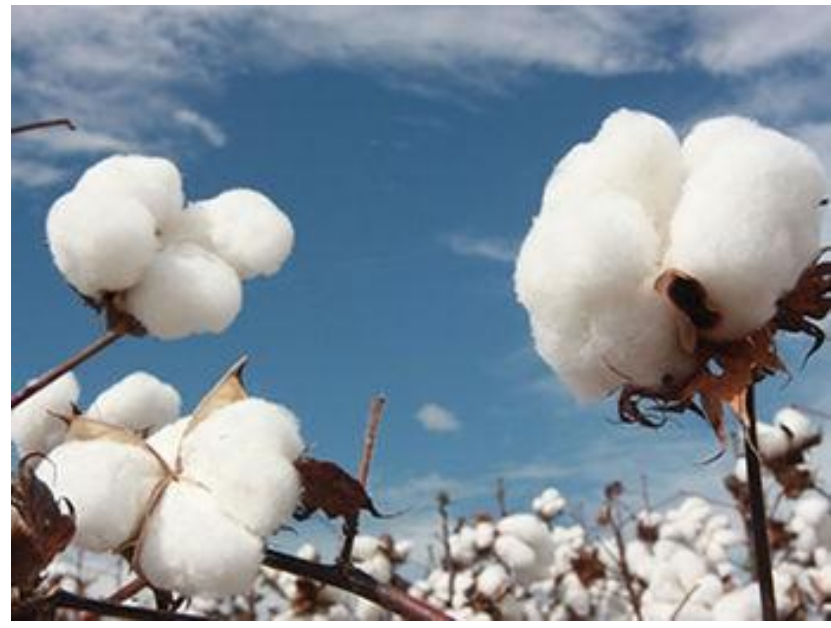

Fonte: O Meu Plano B (2018)

Além das fibras para a produção de tecidos, o algodão tem outras finalidades. De acordo com Passos (1982), dessa planta, quase tudo se aproveita, e variados produtos são desenvolvidos, como: óleos, tecidos cirúrgicos, algodão hidrófilo - indicado para uso hospitalar -, entre outros. Conhecendo as fibras utilizadas na indústria têxtil, com ênfase no algodão, é surpreendente saber que o seu cultivo é realizado pelo homem há milhares de anos, sendo registrado na história mesmo antes de Cristo.

As fibras foram estudadas e usadas pelo ser humano ao longo dos séculos, na produção de peças do vestuário. Na contemporaneidade, observando os problemas ambientais, cabe ao homem identificar as fibras que são sustentáveis e que causam menos danos ao meio ambiente, pensando no tempo necessário para a sua reposição na natureza, sem comprometer as gerações futuras.

\section{História do Algodão no Brasil e no Mundo}

Conhecer a história do ser humano é resgatar acontecimentos, fatos, tradições, experiências que o homem vivenciou em certo período. Estudar acontecimentos do passado, muitas vezes, auxilia-nos a entender aspectos do presente. Os subtítulos a seguir apresentam a história do algodão no Brasil e no mundo, relatando datas e locais em que a planta foi encontrada, questões relativas à economia da época e estados em que atualmente as espécies são cultivadas.

\subsection{História do Algodão no Mundo}

A vestimenta foi uma das criações humanas gerada pela necessidade, para esconder a nudez, para proteger do frio e do sol, para ostentar poder. Na Antiguidade, as vestimentas eram feitas de pele de animais, mas, conforme o homem evoluía, este realizava novas descobertas. 0 algodão foi descoberto há muitos séculos a.C.

Segundo Aguiar Neto (1996), há indícios da origem do algodão no ano 12000 a.C. Na Índia ele foi conhecido no ano 3000 a.C., concordando as autoridades que a Índia foi o principal país que utilizou o algodão, antes de 2500 a.C. Passos (1982, p. 1) escreve que, "em escavações arqueológicas nas ruínas de Mohenjo-Daro, no Paquistão, encontrou-se vestígios de tela e cordão de algodão com mais de 5000 anos". O algodão foi uma das principais fibras usadas na produção 
de tecidos, assim como o linho e a lã.

Por muito tempo, acreditou-se que o algodão foi introduzido pelos países exploradores e que era um produto do Velho Mundo. Hoje, os cientistas têm dados que revelam que os indígenas das Américas do Norte e do Sul, da Ásia e da África já usavam as fibras de algodão para a confecção de fios e tecidos, mostrando que o algodão era cultivado simultaneamente em todo o mundo (AGUIAR NETO, 1996). Outras descobertas históricas comprovam que a cultura do algodão é antiga. Araújo e Castro (1986) relatam que em uma gruta no México, na cidade de Tehuacán, se encontraram restos de tecido de algodão que datavam de 5800 a.C. Também na China, no Paquistão, na Índia e no Egito se fizeram achados semelhantes.

A palavra algodão tem origem árabe, al coton. Foram os árabes que introduziram o algodão e a sua manufatura na Europa, mas a fibra tornou-se conhecida mesmo na época das Cruzadas, depois do século $X$, quando Gênova e Veneza começaram a importar a matéria-prima das Índias (PASSOS, 1982). Até o século XVIII, a lã ocupava o primeiro lugar em consumo entre as fibras na Europa. Em 1736, a mistura de algodão com linho foi permitida em alguns tecidos na Inglaterra e se proibiu a importação de manufatura da Índia. Dessa época em diante, a cultura do algodão cresceu rapidamente, com o desenvolvimento de maquinários de fiação e tecelagem.

Nos Estados Unidos, o algodão apareceu na Carolina do Norte e na Geórgia em 1785. Naquela época, após a colheita, eram utilizados descaroçadores em rolo na limpeza do algodão, instrumento com pouco rendimento. Em 1792, Eli Whitney inventou o descaroçador de serra, que aumentou significativamente a produção nessa etapa. Isso permitiu o avanço no desenvolvimento da cultura do algodão no país, tornando-se a maior do mundo naquela época. Exemplo disso é o fato de que, em 1780, os Estados Unidos exportavam cerca de 73 mil fardos exportados de algodão e em 1860 alcançaram cerca de quatro milhões. "Outros países, entretanto, passaram também a ser grandes produtores de algodão, tais como a Rússia, a China, a Índia, o Paquistão, o Egito e o próprio Brasil, sem contar outras tantas nações menores produtoras" (PASSOS, 1982, p. 2).

Na história da humanidade, o algodão teve importante relação para a economia de alguns países. Escrevem Araújo e Castro (1986) que na América do Norte, mais precisamente nos estados do Sul dos Estados Unidos, a partir do século XVIII, a cultura do algodão passou por aperfeiçoamentos e esteve ligada a economia e à história do país. Estabeleceu-se uma rica sociedade, que utilizava mão de obra escrava, oriunda da África, nas plantações anuais e colheita manual do algodão.

Conforme Aguiar Neto (1996), sob o nome Gossypium Linnaeus, o algodão está dividido em quatro espécies primárias: Gossypium indicum, que é uma variedade que tem flor amarela e fibra curta encontrada no Egito, na Ásia Menor, na Índia, na China e na Arábia; Gossypium Arboreum, com flores vermelhas e que, quando desenvolvido, chega a 5 metros de altura, natural do Egito, Índia, China, Índia Ocidental e América do Sul; Gossypium Hirsutum, a espécie mais importante, pois abrange os algodões upland, dos Estados Unidos; e Gossypium barbadense, a que pertencem os algodões egípcios, peruanos, alguns do Brasil, da América Central, das Índias Ocidentais e de Barbados, ou o famoso sea island, algodão conhecido por ter fibras excepcionalmente longas, fortes e sedosas.

Em vários países do mundo, o algodão é reconhecido como produto que movimenta a economia, aquecendo toda a cadeia têxtil. No Brasil ele já teve períodos muito fortes e hoje cresce 
modestamente, com o acompanhamento de associações e pesquisas na área.

\subsection{História do Algodão no Brasil}

Considerando a data de chegada dos europeus ao Brasil, os indígenas que aqui estavam já cultivavam o algodão e transformavam as fibras em fios e tecidos. Nas obras de Pero de Magalhães Gândavo, têm-se relatos que as camas dos índios eram confeccionadas com fios de algodão. Os indígenas faziam mingau esmagando e cozinhando o caroço do algodão e com as folhas curavam feridas, além de aplicarem a fibra em outras utilidades (PASSOS, 1982). A espécie de algodoeiro nativa no Brasil é o alotetraploide (Gossypium mustelinum), que entrou na complexa composição genética do algodoeiro arbóreo, singular no Nordeste brasileiro (ARAÚJO; GOULART, 2004). Com a colonização, começaram as pequenas culturas de algodão nativo, que tinham pequena expressão; não passavam de "roças" em volta das habitações, e o artesanato têxtil era trabalho de mulheres (índias e escravas). Segundo Passos (1982, p. 4), "foi só pelos meados do século XVIII, com a Revolução Industrial, que o algodão foi transformado na principal fibra têxtil e no mais importante produto das Américas".

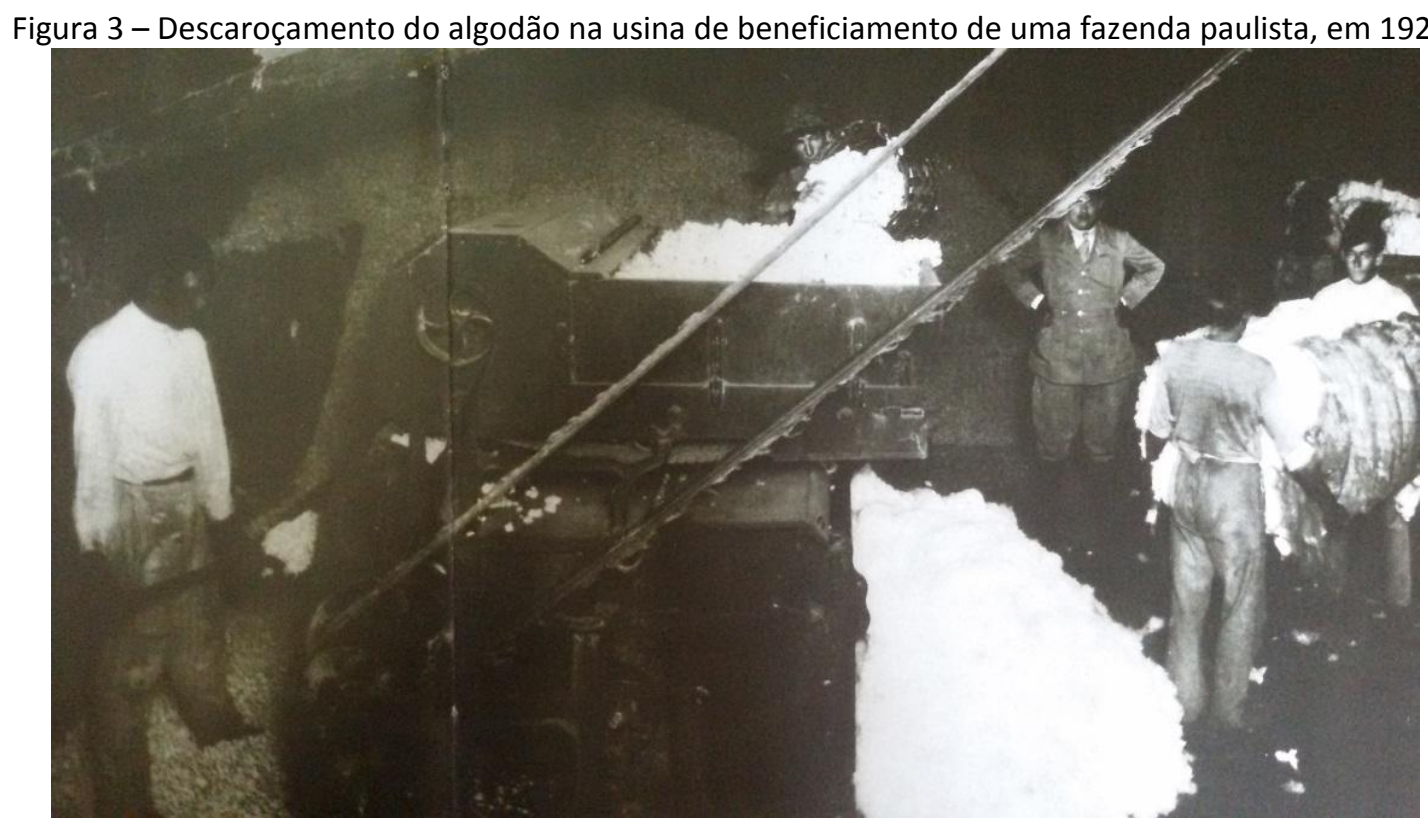

Fonte: MATHIAS (1988, p. 15)

A figura 3 acima, apresenta uma usina de beneficiamento de algodão em São Paulo realizando o descaroçamento. Passos (1982) relata que o estado do Maranhão foi o primeiro a despontar na produção do algodão, seguido de toda a Região Nordeste. O primeiro descaroçador de serra foi instalado em Pernambuco, em 1820. São Paulo teve a primeira fábrica de tecidos em 1813, e o primeiro descaroçador, em 1851, mas os Estados Unidos já alavancavam sua produção na cultura do algodão, exportando grandes quantidades, causando a decadência nos negócios do Brasil, que também tinham concorrência com outras culturas, como o café, que monopolizava o agronegócio em São Paulo. Em 1860, com a guerra de secessão nos Estados Unidos, desencadeouse um novo surto algodoeiro no Brasil que durou pouco mais de 10 anos. O Brasil cultivava o algodão arbóreo e, posteriormente, foi introduzido no país o algodão herbáceo, sendo São Paulo o primeiro produtor e exportador dessa fibra. 
O algodão crescia no país, com pesquisas agronômicas e associações voltadas para a cultura. Hoje o algodão é cultivado em diversos estados, como: Bahia, Paraná, Goiânia, Maranhão, Minas Gerais, Mato Grosso, Mato Grosso do Sul, João Pessoa, entre outros (ABRAPA, 2018). Assim como crescia o agronegócio do algodão no Brasil, também as indústrias têxteis despontavam, completando a cadeia do vestuário e oferecendo à população inúmeros produtos da moda.

O agronegócio do algodão no Brasil, assim como no mundo, tem atualmente grande importância para a economia e para os agentes que fazem parte da cadeia têxtil/moda. Em todos os processos existem ramificações, clientes e fornecedores, todos contribuindo para um dos maiores segmentos do mercado. O resultado de todo esse trabalho chega com força aos consumidores, com uma infinidade de peças diferentes em mãos a cada coleção e o desejo por novas aquisições, alimentando o paradigma do consumismo.

\section{Fatores que motivam os agentes consumidores nas opções de compras de roupas e tecidos em geral}

Para o desenvolvimento dos produtos de moda, os designers utilizam diversos materiais na sua criação. Como já verificamos, um dos mais recorrentes na indústria têxtil é o algodão. Por ser uma fibra natural, leve e confortável, é bastante procurada no momento da compra. Além das características citadas anteriormente, a busca por diferenciação e exclusividade também impulsiona o consumo, que é acelerado em todos os segmentos, principalmente na moda. Segundo Castilho e Demetresco (2011, p. 18), "era a diferenciação constante que movia (e ainda hoje move) a demanda por novos estilos e produtos, gerando, dessa forma, a movimentação da economia através do aumento do consumo". Os produtos da indústria da moda e demais produtos que circulam são desenvolvidos com base na noção de exclusividade e inovação, para oferecer e incentivar o consumo de objetos, muitas vezes desnecessários. Conforme Sabrá (2016, p. 44), "para os consumidores, esses objetos passam a trazer uma necessidade imposta externamente, vinculada a uma noção de pertencimento: a posse de um produto que lhes dará a falsa sensação de inclusão simbólica na sociedade a que desejam pertencer".

Obter uma peça de roupa nova pode representar a realização de um desejo. Forty (2007), em seu livro Objetos do desejo: design e sociedade desde 1750, explica que os clientes sempre esperam novas opções de objetos, constantemente buscando produtos atuais. Esse desejo pode ser motivado por fatores pessoais ou externos, como a vida social. A aquisição de uma peça do vestuário pode ser incentivada por inúmeros fatores relacionados com o produto, desde criação, embalagem, desenho da marca, webdesign do site, campanhas publicitárias, clientes que utilizam o produto; tudo motiva ou não uma compra (SABRÁ, 2016). Isso significa que os agentes consumidores, muitas vezes, adquirem objetos incentivados por fatores associados ao valor simbólico do produto. Forty (2007) exemplifica essa teoria descrevendo que "os produtos de designers reconhecidos e aclamados atraíram preços substancialmente mais altos do que objetos de designers anônimos" (FORTY, 2007, p. 323). Também Scholz (2009) relata que os objetos possuem valor simbólico: "O habitus de consumo de um bem recebe um valor social pelo uso social a que é submetido, passando a ser condicionado ao capital simbólico atribuído pelo consumidor e a sua necessidade de consumo, frente à distinção promovida" (SCHOLZ, 2009, p. 89).

Por meio da aquisição e exibição de uma peça do vestuário, pode-se expressar mais do que a roupa representa, envolvendo características próprias da pessoa. Conforme Schulte e Lopes 
(2008, p. 37), "é inerente ao ser humano a necessidade de se expressar, se comunicar. Através do vestuário expressam-se desejos, sentimentos, convicções, crenças, ideais, entre outros, e a própria personalidade". Outros autores relatam semelhante percepção: "O status de ter, exibir, e ostentar também pode ser considerado como simbólico, uma vez que o produto de vestuário não é inocente de considerações políticas econômicas, mas sim considerado expressão de um personagem, de um grupo, ou mesmo de uma sociedade" (SABRÁ, 2016, p. 45). Percebe-se que a sociedade tem significativa influência na opção de compra, na vontade de adquirir determinada peça do vestuário. É necessário inspirar essa mesma sociedade para que as escolhas dos produtos sejam melhores, levando em conta a urgente busca pela sustentabilidade. "O produto do vestuário de moda exerce forte influência sobre as pessoas. Assim, propor produtos desenvolvidos com um apelo ecológico é um meio de estimular e consolidar o desenvolvimento sustentável e o consumo consciente" (SCHULTE; LOPES, 2008, p. 42).

O consumo desenfreado na sociedade contemporânea tornou-se alvo de debates, relacionado com a sustentabilidade e com pesquisas de demanda de mercado e envolvido com temas em diversas áreas, tratado como assunto trivial, mas a compra supérflua não deveria ser habitual. Sabrá (2016, p. 71) explica: "O desejo de consumo, portanto, não é natural na biologia dos homens, mas algo implantado socialmente para levar a consumir objetos que 'estão na moda'. Moda está diretamente ligada ao efeito efêmero de consumo pelo consumo que foi produzido pelo modo de produção capitalista".

O consumismo é uma realidade, e reverter isso é quase missão impossível. Devem-se identificar mecanismos para lidar com esse cenário que se configurou e se consolidou no século XX (SCHULTE; LOPES, 2008). O consumismo no mundo da moda faz parte de um sistema que envolve governo, empresas, consumidores, mas não é uma situação natural, e sim imposta pelos agentes do processo. Segundo Sabrá (2016, p. 69), "o indivíduo, consumidor ou sujeito social, não pode ser considerado dono de sua capacidade de escolha, ou sujeito do seu desejo de consumo, mas apenas vítima de um 'novo' produto têxtil imposto pelos designers". Percebemos que os designers também têm importante papel na criação de peças do vestuário, que sua participação deve ser realizada com responsabilidade e consciência. No entanto não são apenas os designers os responsáveis por impulsionar a aquisição de produtos do vestuário. "O consumidor, a indústria, o criador de novos produtos, todos têm papéis determinantes na consolidação deste paradigma" (SCHULTE; LOPES, 2008, p. 32).

Os produtos desenvolvidos e distribuídos para venda passam por pesquisas de tendências e devem ser colocados no mercado como necessários e essenciais, deixando os agentes consumidores com desejo de obter tais peças. Sabrá (2016, p. 27) relata que "um produto da cadeia têxtil, segmentado no vestuário, enquadrado e dito como produto de moda, só será reconhecido pelo mercado quando for notoriamente aclamado pelo meio que o constitui". O autor conclui argumentando que o designer, que criou o produto, também faz parte do meio em que está inserido. Os produtos são situados conforme resultados de pesquisas, já com data de vencimento e sofrem forte influência da sociedade (SABRÁ, 2016). A criação de produtos efêmeros e de commodity é considerada como natural e imprescindível para as empresas, com a justificativa de que precisam dessa constante busca por novos produtos para crescerem e se manterem competitivas. Infelizmente, essa prática reflete diretamente nos problemas relacionados com o meio ambiente e a sustentabilidade, pois "os ciclos curtos de vida destes produtos e o apelo ao consumismo representam um entrave ao desenvolvimento sustentável" (SCHULTE; LOPES, 2008, 
p. 32).

Segundo Sabrá (2016), quando os agentes consumidores desejam algum produto do vestuário, normalmente produto de grife, e este não é urgentemente necessário, mas trará distinção social, não conhecem os processos da cadeia têxtil que envolve esse produto. Além dos processos, que exigem tecnologia, maquinário moderno e os mais variados produtos, também existem as pessoas que atuam nas respectivas áreas. Todo o processo produtivo na cadeia têxtil, desde a concepção de um produto, produção e entrega, envolve inúmeros agentes, muitas vezes não conhecidos pelos consumidores, como as pessoas que plantam, cultivam e colhem o algodão, entregando-o para a produção de fios e posteriormente para a confecção dos tecidos, envolvendo técnicos, maquinários, pessoal direto na produção, todos gerando insumos para a cadeia têxtil e para o produto final (SABRÁ, 2016).

Essa conexão entre designers, sociedade e agentes consumidores pode ser utilizada de maneira benéfica para os próprios seres humanos. Haja vista as questões culturais como desejo de compra, simbólica ou necessária; valores pessoais; influência da sociedade; e alta produção de artigos do vestuário continuarão exercendo força e mantendo ativo o consumismo, é essencial pensar em produtos com materiais sustentáveis. Segundo Sabrá (2016, p. 76), a "peça de moda pode ter sido produzida com determinada tecnologia têxtil com desenvolvimento de fibras, fios, armações e tecidos, ou de acabamento de superfície, no intuito de apresentar claramente ao consumidor um valor simbólico agregado que o estimulará a consumi-la". Dessa forma, deixa claro que o desenvolvimento e os tipos de materiais usados na criação podem influenciar na compra de um produto. Então, deve-se investir em matéria-prima e em processos de menor agressão ao meio ambiente. Para Schulte e Lopes (2008, p. 36), "em alguns países já existe uma legislação rígida obrigando as indústrias a se adequarem para diminuir os danos ao meio ambiente, também há consumidores conscientes que procuram por produtos ecologicamente concebidos, que se preocupam com a natureza e com as gerações futuras".

Empregar materiais adequados na cadeia do vestuário, como o algodão, pode contribuir com questões ambientais. $O$ algodão cultivado de maneira convencional - muitos hectares utilizados no plantio, ano após ano, mediante agrotóxicos e fertilizantes químicos - hoje em dia vem sendo substituído pela cultura do algodão sustentável. "A escolha mais criteriosa dos produtos consumidos, o uso de combustíveis alternativos, e principalmente a redução do consumo, entre outras ações, são de grande importância para a minimização dos problemas ambientais e para a promoção do desenvolvimento sustentável" (SCHULTE; LOPES, 2008, p. 33).

Entende-se que o paradigma do consumismo no segmento do vestuário não será eliminado; faz parte de um contexto da vida dos agentes consumidores, envolvendo questões além das necessidades. Reflete desejos simbólicos, mas pode ser transformado. As peças do vestuário precisam ser desenvolvidas de maneira consciente, com matéria-prima sustentável e processos que envolvam o mesmo cuidado, agregando informações acerca dos efeitos positivos desses materiais na produção, que devem ser melhores ao meio ambiente e ao ser humano. Essa iniciativa será refletida na sociedade e consequentemente no agente consumidor, com opções de peças diferenciadas pela qualidade e durabilidade, criando um laço afetivo com o produto. 


\section{Cultivo do Algodão Sustentável no Brasil}

Considerando que a principal fibra utilizada na indústria têxtil/da moda é a fibra do algodão e que o consumo de moda envolvendo essa matéria-prima é forte, faz-se importante conhecer situações atuais relacionadas com a cultura do algodão sustentável que refletem diretamente no meio ambiente. $\mathrm{O}$ algodão sustentável tem se mostrado uma alternativa viável, preocupa-se com questões de sustentabilidade e possui a consciência necessária aos problemas ambientais.

\subsection{Sustentabilidade e Meio Ambiente}

A indústria têxtil e da moda é considerada uma das mais poluentes do mundo. Tendo em vista a demanda por produtos e sua grande capacidade produtiva, ela movimenta fortemente a economia e é foco no mundo inteiro. Segundo dados da ABIT (2015-2018), quanto ao volume de artigos de vestuário produzidos, cabe à Ásia $73 \%$ da produção, ficando o Brasil com a quarta posição entre os maiores produtores mundiais.

Os altos índices de produção refletem-se em toda a cadeia produtiva do setor têxtil e de moda, e todos os processos de manufatura são responsáveis diretamente pelo impacto dos seus resíduos na natureza e pela quantidade de lixo produzido, além de os clientes finais terem importante responsabilidade nos seus atos, com a compra, o uso e o descarte dos produtos provenientes da indústria da moda.

A maior parte da população, principalmente a classe baixa, que possui menos informação, não conhece o processo produtivo das peças do vestuário, os caminhos percorridos até chegar ao consumidor nem o prejuízo causado à natureza. Ao comprar uma simples camiseta de algodão, por exemplo, Berlim (2012, p. 32) descreve que esse produto consumiu "160 gramas de agrotóxico, uma determinada quantidade de energia e que causou danos sérios ao solo, à água e àqueles que trabalharam no cultivo do algodão". Essas informações não são transparentes aos agentes consumidores.

A utilização de agrotóxicos e fertilizantes nas plantações de algodão é justificada pela necessidade de eliminar ou combater pragas que danificam a matéria-prima, mas isso é nocivo às pessoas, ao solo e ao lençol freático. Se aplicados sem controle, sem equipamentos de proteção e sem acompanhamento, podem causar cânceres e outros problemas de saúde. Morgan (2015) relata que cerca de 70 a 80 crianças de uma comunidade de Punjab, na Índia, possuem retardo mental e outros problemas neurológicos em razão do contato com produtos químicos provenientes das pulverizações das lavouras de algodão. Os próprios agricultores sofrem muito com as doenças. A família, em condições vulneráveis, não consegue obter os tratamentos necessários para possibilitar a reabilitação aos seus membros, causando, muitas vezes, a morte de adultos e crianças. Sem provas concretas da relação da indústria de pesticidas com esses acontecimentos, as comunidades locais sofrem sem receber recursos ou indenizações e cada vez mais imergem nesse cenário desumano.

É fato que as questões ambientais estão sendo debatidas por algumas corporações com mais seriedade, sendo pauta em reuniões de empresas e governos, e muitos buscam adotar medidas sustentáveis. No Brasil, a Associação Brasileira dos Produtores de Algodão (Abrapa) introduziu e incentiva o cultivo do algodão sustentável, resultando em um processo regulamentado, com selo do Algodão Brasileiro Responsável (ABR) e certificação internacional 
Better Cotton Initiative (BCl), que significa Iniciativa por um Algodão Melhor.

\subsection{Algodão Sustentável com Certificações}

A Abrapa foi criada no dia 7 de abril de 1999. Ela criou instrumentos que atestam a conformidade mínima que o produtor (por unidade produtora/fazenda) deve obter para conseguir a certificação. Esse produtor deve ser associado a uma das associações estaduais de produtores de algodão, que, em processo de certificação, avalia a fazenda produtora com base nos critérios de sustentabilidade aplicados no regulamento do Programa ABR (ABRAPA, 2013). Suas finalidades são garantir e desenvolver rentabilidade ao agronegócio por meio da união dos seus agentes, com foco na sustentabilidade e atuação política, social e econômica, fomentando e ampliando o setor, gerando melhoria e aumento da produção. Com o compromisso de tornar a cotonicultura brasileira conhecida e competitiva nacional e internacionalmente, o órgão busca a melhoria contínua, atuando na qualidade, rastreabilidade e sustentabilidade. É composta de 10 associações estaduais: Associação Baiana dos Produtores de Algodão (Abapa), na Bahia; Associação dos Cotonicultores Paranaenses (Acopar), no Paraná; Associação Goiana dos Produtores de Algodão (Agopa), em Goiás; Associação Maranhense dos Produtores de Algodão (Amapa), no Maranhão; Associação Mineira dos Produtores de Algodão (Amipa), em Minas Gerais; Associação Matogrossense dos Produtores de Algodão (Ampa), no Mato Grosso; Associação Sul-Mato-Grossense dos Produtores de Algodão (Ampasul), no Mato Grosso do Sul; Associação Piauiense dos Produtores de Algodão (Apipa), no Piauí; Associação Brasileira dos Produtores de Algodão (Appa), em São Paulo; e Associação dos Produtores de Algodão do Tocantins (Apratins), no Tocantins. Hoje, a Abrapa representa $99 \%$ de toda a área plantada, 99\% da produção e 100\% da exportação de algodão no Brasil. Sua administração é feita por uma assembleia geral de representantes, com eleição em cada safra e gestões bianuais. Para auxiliar na administração, montam-se grupos de trabalho, que atuam na áreas de comercialização e rentabilidade, tecnologia, marketing, sustentabilidade, relações institucionais e qualidade (ABRAPA, 2018).

A sustentabilidade na sociedade contemporânea está à frente das decisões e estratégias governamentais, entidades representativas de todos os setores, empresas e corporações; há demanda crescente por produtos e serviços gerados sem agressão ao meio ambiente e com respeito à dignidade do trabalhador (ABRAPA, 2018). Podemos conceituar sustentabilidade como o "conjunto de conhecimentos e atitudes, os quais definem ações e atividades humanas visando suprir as necessidades atuais sem comprometer o futuro das próximas gerações" (ABRAPA, 2018).

Considerando que questões relativas ao meio ambiente são importantes e que o consumidor está progressivamente motivado a adquirir peças que disponibilizem informações acerca da qualidade dos produtos, cada vez mais produtores e empresas aderem ao algodão sustentável. Para o algodão ser qualificado como sustentável e receber certificação e selo, o produtor associado deve cumprir requisitos que fazem parte do Regulamento da $A B R$, tais como: ter cadastro completo apresentando documentos comprobatórios; escolher se participa do licenciamento para comercialização de $\mathrm{BCl}$, o que é opcional; fornecer informações referentes às plantações, para elaboração do relatório de indicadores de base e indicadores de resultados; e passar por avaliação de equipe técnica, baseada nos critérios de sustentabilidade adotados pelo Programa ABR, que levantará o nível de conformidade da fazenda produtora (ABRAPA, 2013).

Para ter direito ao Certificado de Conformidade ABR, a unidade produtora (fazenda), por Cadastro Específico do Instituto Nacional do Seguro Social (CEI) ou Cadastro Nacional de Pessoa 
Jurídica (CNPJ), deve atingir a cada safra sucessiva, a partir de sua adesão ao Programa ABR, níveis de conformidade, como: na primeira safra (ano safra), no mínimo $85 \%$, de acordo com a lista de verificação para certificação da propriedade; e da segunda safra em diante o seu nível de conformidade elevar-se progressivamente em, no mínimo, $2 \%$ a cada nova safra, até atingir o objetivo máximo e ideal do Programa ABR, ou seja, 100\%. Como resultado do processo de certificação objeto desse regulamento, é emitido o certificado de conformidade pelo Programa $A B R$ e autorizada a emissão do selo $A B R$. As produtoras deverão exercer melhoria contínua e podem ter a certificação cancelada se no período de validade praticar infrações, como está no Regulamento ABR (ABRAPA, 2013).

Sob a liderança da Abrapa, que atua pela causa da sustentabilidade no Brasil, o agronegócio do algodão é potencializado com o Programa $A B R$, o qual possui um acordo de benchmarking com a $\mathrm{BCl}$, que é um órgão como o $\mathrm{ABR}$, mas a nível mundial, que visa melhorar a subsistência e o desenvolvimento econômico nas áreas cotonicultoras e reduzir o impacto ambiental do algodão. Envolve agricultores que participam num ciclo contínuo de aprendizagem e melhorias e é o mecanismo central para avaliar se os agricultores podem cultivar e vender better cotton.

As fazendas produtoras e parceiras do $A B R$ que querem obter também a certificação $\mathrm{BCl}$ devem cumprir alguns princípios, como: adotar um programa de controle de pragas, prezando por uma lavoura saudável e prevenindo o ataque de pragas por meio do aprimoramento de populações de insetos benéficos; utilizar água de maneira eficiente, zelando por sua disponibilidade e otimizando o uso; cuidar da saúde do solo, mantendo e incrementando a estrutura e fertilidade, aplicando nutrientes conforme a necessidade da cultura e da época, melhorando a aplicação e a dosagem, buscando minimizar a erosão e contendo a movimentação do solo, a fim de proteger fontes de água potável e outros cursos d'água contra o escoamento de superfície; além de conservar os hábitats naturais, adotando práticas que aumentem a biodiversidade na propriedade do produtor de algodão; zelar e preservar pela qualidade da fibra, cuidando na colheita e no armazenamento do algodão em caroço, de modo que se minimizem impurezas, danos e contaminações; e promover relações justas de trabalho, prezando pela liberdade da associação, que pode desenvolver organizações de acordo com seus interesses.

De acordo com a Convenção 138 da Organização Internacional do Trabalho (OIT), que proíbe qualquer trabalho infantil, a idade mínima estabelecida para inserção no mercado algodoeiro é 18 anos e o emprego deve ser escolhido livremente; nenhuma mão de obra deve ser compulsória ou forçada. Isso inclui mão de obra traficada ou escrava para pagamento de dívidas (BETTER COTTON, 2018). A figura 4 apresenta um treinamento numa fazenda de algodão no Amapá. 
Figura 4 - Treinamento em fazenda de algodão no Amapá.

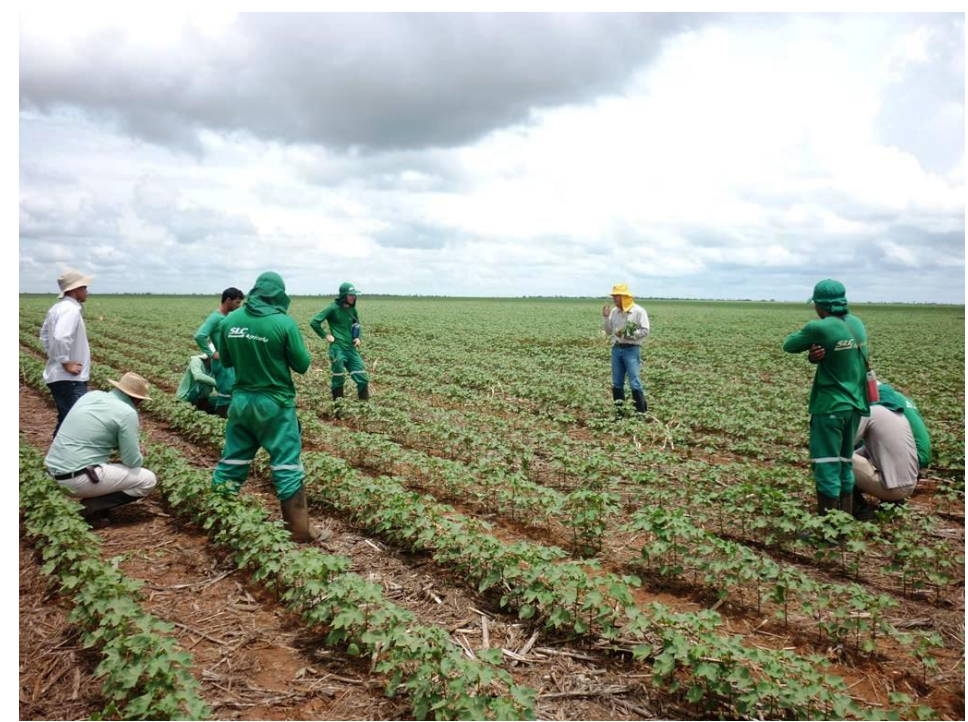

Fonte: http://www.amapa-ma.com.br/2016/03/08/treinamento-de-mip-mid-e-mipd. Acesso em: 29 jan. 2018.

O produtor precisa cumprir todos os critérios estabelecidos. Caso contrário, terá disponível um plano de apoio e desenvolvimento para que possa se ajustar em certo prazo. Segundo ECycle (2018), essas certificações são benéficas, pois a produção de algodão é responsável pela sobrevivência de mais de 100 milhões de produtores no mundo todo e por milhares no Brasil, que dependem do algodão na cadeia têxtil. Sem contar os subprodutos gerados pela fibra, como óleo, biodiesel, farelo para alimentação animal e outros.

Em comparação com outras fibras utilizadas na indústria têxtil, o algodão é uma das alternativas mais sustentáveis para a produção de tecidos. Por ser biodegradável, as peças confeccionadas com algodão prejudicam menos o meio ambiente quando descartadas na natureza e não soltam microplástico durante a sua utilização, como as fibras sintéticas. Também é possível ser ambientalmente amigáveis e controlados os processos de fabricação dos produtos que usam essa matéria-prima, diminuindo o impacto ambiental das indústrias têxteis para sociedade.

\section{Considerações Finais}

O artigo destacou a cultura do algodão sustentável, empreendimento que vem sendo utilizado pelos produtores que buscam minimizar o impacto ambiental gerado pela atividade e também auxiliar os agentes consumidores no momento da compra, dando opção de materiais sustentáveis. Levantaram-se relatos conceituais acerca das fibras têxteis, a história do algodão no Brasil e no mundo, os fatores que motivam os agentes consumidores às opções de compra de roupas e tecidos e o que são as certificações $A B R$ e $B C l$, ressaltando o que é necessário para sua obtenção e os benefícios.

As fibras têxteis são uma grande descoberta para o ser humano, que as retirou da natureza e as transformou, criando quimicamente materiais artificiais e sintéticos. Por meio das fibras, vários materiais são desenvolvidos e aplicados em diversas áreas do mercado. Salientaram-se as principais fibras utilizadas na indústria têxtil e a natureza delas, enfatizando que a fibra do algodão é a mais usada em termos mundiais e movimenta fortemente a economia. Seu cultivo, realizado de maneira sustentável, é o mais adequado para a área do vestuário. 
A fibra do algodão é a mais empregada no mundo e historicamente também uma das mais antigas. Sua descoberta vem de muitos anos a.C., em inúmeros países do mundo, como Egito, China, Índia, Paquistão, Rússia, Peru, Estados Unidos e o próprio Brasil. Pesquisas revelam que os indígenas brasileiros já utilizavam tal fibra em fios para cordas e camas, assim como em demais localidades, relatos que descrevem que a fibra do algodão já tinha como função principal a mesma que tem hoje em dia: a aplicação em roupas e tecidos em geral.

$\mathrm{O}$ artigo ressaltou fatores que levam os agentes consumidores a adquirir uma nova peça do vestuário, evidenciando que o consumidor em si é influenciado por vários aspectos. Muito além da necessidade, existe a realização de um desejo, na maioria das vezes, simbólico, instigado pela própria sociedade. Outros fatores, que vêm de dentro das indústrias, são as pesquisas e o encorajamento pela compra feita pelos designers, que desenvolvem e criam tendências, estas também lançadas pela sociedade, com a finalidade de otimizar as vendas.

Considerando que a indústria têxtil e do vestuário em geral é uma das mais poluentes e que as aquisições, no momento, não serão minimizadas, em razão dos fatores citados, é fundamental que se busquem alternativas sustentáveis, como a escolha da matéria-prima. A cultura do algodão sustentável, com certificação nacional ( $A B R$ ) e internacional $(B C l)$, vem ao encontro dessa premissa. As fazendas produtoras têm responsabilidade de se adequar às normas estabelecidas e se comprometer com questões sustentáveis, econômicas e sociais, recebendo certificação de qualidade e selo.

Conclui-se, com base nas informações apontadas no artigo, que, à medida que o ser humano demonstrar sua responsabilidade em relação ao meio ambiente, inserindo práticas sustentáveis na produção da matéria-prima e nos demais processos dentro do ciclo, isso influenciará toda a cadeia, ampliando a adoção de melhores hábitos, desde a gestão das empresas até o consumidor final. Já existem elos na cadeia têxtil que, incentivados pela procura de produtos amigáveis ao meio ambiente, utilizam o algodão sustentável nas suas indústrias, dando continuidade ao processo de sustentabilidade nas demais etapas, como no beneficiamento/acabamento, com utilização de corantes naturais para o tingimento dos tecidos. Dessa forma, o agronegócio do algodão sustentável precisa ser incentivado, pois ele supre a demanda da matéria-prima e é menos agressivo ao meio ambiente.

\section{Referências}

AGUIAR NETO, Pedro Pita. Fibras têxteis. Rio de Janeiro: Senai/CNPq, 1996. v. 1.

ARAÚJO, Alderi Emídio; BELTRÃO, Napoleão Esberard de Macêdo. Algodão: o produtor pergunta, a Embrapa responde. Brasília: Embrapa Informação Tecnológica, 2004.

ARAÚJO, Mário D.; CASTRO, E. M. de Melo. Manual de engenharia têxtil. Lisboa: Fundação Calouste Gulbenkian, 1986.

ASSOCIAÇÃO BRASILEIRA DA INDÚSTRIA TÊXTIL (ABIT). O poder da moda: cenários, desafios, perspectivas. Agenda de competitividade da indústria têxtil e de confecção brasileira 2015 a 2018. Disponível em: <www.abit.org.br>. Acesso em: 18 jan. 2018.

ASSOCIAÇÃO BRASILEIRA DOS PRODUTORES DE ALGODÃO (ABRAPA). Portal. Disponível em: $<$ http://www.abrapa.com.br>. Acesso em: 15 jan. 2018.

Regulamento do Programa Algodão Brasileiro Responsável (ABR) com opção de adesão 
ao Programa Better Cotton (BCl). Abrapa, 2013. Disponível em: <http://www.abrapa.com.br/BibliotecaSustentabilidade/ABR\%20\%E2\%80\%93\%20Algod\%C3\%A30 \%20Brasileiro\%20Respons\%C3\%A1vel/Regulamento_ABR\%202013.14.pdf>. Acesso em: 16 jan. 2018.

\section{ASSOCIAÇÃO MARANHENSE DOS PRODUTORES DE ALGODÃO (AMAPA). Treinamento em fazenda} de algodão no Amapá. 2016. Disponível em: <http://www.amapama.com.br/2016/03/08/treinamento-de-mip-mid-e-mipd/>. Acesso em: 29 jan. 2018.

BERLIM, Lilyan. Moda e sustentabilidade: uma reflexão necessária. São Paulo: Estação das Letras e Cores, 2012.

BETTER COTTON. 0 programa de garantia Better Cotton. Disponível em: <https://bettercotton.org>. Acesso em: 29 jan. 2018.

CASTILHO, Kathia; DEMETRESCO, Sylvia (Orgs.). Consumo: práticas e narrativas. São Paulo: Estação das Letras e Cores, 2011.

CHATAIGNIER, Gilda. Fio a fio: tecidos, moda e linguagem. São Paulo: Estação das Letras e Cores, 2006.

DANIEL, Maria Helena. Guia prático dos tecidos. Osasco: Novo Século, 2011.

ECYCLE. Certificação BCl: uma forma sustentável de produzir algodão. Disponível em: <https://www.ecycle.com.br/component/content/article/67-dia-a-dia/5986-o-que-e-certificacaobci-sustentabilidade-algodao.html>. Acesso em: 18 jan. 2018.

FORTY, Adrian. Objetos do desejo: design e sociedade desde 1750. São Paulo: Cosac Naify, 2007.

MATHIAS, Herculano Gomes. Algodão no Brasil. Rio de Janeiro: Index, 1988.

MORGAN, Andrew. The true cost. Produção: Michael Ross. 2015. Disponível em: <https://itunes.apple.com/us/movie/the-true-cost/id989035329?ign-mpt=uo\%3D6>. Acesso em: 19 jun. 2015.

$O$ MEU PLANO B. Plantação de algodão. Disponível em: <http://www.omeuplanob.com/2016/05/o-que-diz-etiqueta-da-tua-roupa.html>. Acesso em: 12 jan. 2018.

PASSOS, Sebastião Messias de Godoy. Algodão. Campinas: Instituto Campineiro de Ensino Agrícola, 1982.

SABRÁ, Flávio Glória Caminada. Os agentes sociais envolvidos no processo criativo no desenvolvimento de produtos da cadeia têxtil. São Paulo: Estação das Letras e Cores, 2016.

SALEM, Vidal. Tingimento têxtil: fibras, conceitos e tecnologias. São Paulo: Blucher-Golden Tecnologia, 2010.

SCHOLZ, Robinson Henrique. Habitus de classe expressado pelo capital simbólico: uma revisão da obra de Pierre Bourdieu A Distinção. Rio Grande do Sul: Ciências Sociais Unisinos, 2009.

SCHULTE, Neide Köhler; LOPES, Luciana. Sustentabilidade ambiental: um desafio para a moda. Modapalavra, n. 2, p. 30-42, ago./dez. 2008. 